\title{
Valeriana officinalis root extract suppresses physical stress by electric shock and psychological stress by nociceptive stimulation-evoked responses by decreasing the ratio of monoamine neurotransmitters to their metabolites
}

Hyo Young Jung ${ }^{1}$, Dae Young Yoo', Woosuk Kim', Sung Min Nam¹', Jong Whi Kim', Jung Hoon Choi², Youn-Gil Kwak ${ }^{3}$, Yeo Sung Yoon ${ }^{1}$ and In Koo Hwang ${ }^{1 *}$

\begin{abstract}
Background: In this study, we investigate the effects of valerian root extracts (VE) on physical and psychological stress responses by utilizing a communication box.

Methods: Eight-week-old ICR mice received oral administration of VE (100 mg/kg/0.5 ml) or equal volume of distilled water in every day for 3 weeks prior to being subjected to physical or psychological stress for 3 days, which are induced by communication box developed for physical electric shock and psychological stress by nociceptive stimulationevoked responses. The stress condition was assessed by forced swimming test and serum corticosterone levels. In addition, norepinephrine (NE), serotonin (5-HT), and their metabolites such as 3-methoxy-4-hydroxyphenylethyleneglycol sulfate (MHPG-SO ${ }_{4}$ ) and 5-hydroxyindoleacetic acid (5-HIAA) were measured in the hippocampus and amygdala at $1 \mathrm{~h}$ after final stress condition, respectively.

Results: Immobility time and corticosterone levels were significantly increased in both the physical and psychological stress groups compared to the control group. The administration of VE significantly reduced these parameters in both the physical and psychological stress groups. In addition, compared to the control group, physical and psychological stress groups showed significantly increased levels of $\mathrm{MHPG}^{-\mathrm{SO}_{4}}$ and 5-HIAA in the hippocampus and amygdala, respectively. The administration of VE significantly suppressed the increase of $\mathrm{MHPG}^{-\mathrm{SO}_{4}}$ and 5-HIAA in the two stress groups.
\end{abstract}

Conclusion: These results suggest that VE can suppress physical and psychological stress responses by modulating the changes in 5-HT and NE turnover in the hippocampus and amygdala.

Keywords: Valeriana officinalis, Physical stress, Psychological stress, Serotonin, Norepinephrine, Hippocampus, Amygdala

\footnotetext{
* Correspondence: vetmed2@snu.ac.kr

'Department of Anatomy and Cell Biology, College of Veterinary Medicine, and Research Institute for Veterinary Science, Seoul National University, Seoul 151-742, South Korea

Full list of author information is available at the end of the article
} 


\section{Background}

Root extracts from Valeriana officinalis (VE) are popular herbal supplements and are widely used in the treatment of sleep disorders, anxiety, and epilepsy [1]. VE shows protective effects against neurodegenerative diseases such as Parkinson's disease [2,3] and Alzheimer's disease [4]. VE tinctures have anti-oxidant effects, as indicated by the finding that the tinctures can inhibit the thiobarbituric acid-reactive substance production and deoxyribose degradation induced by various pro-oxidants in rat brain homogenates [5]. In addition, VE can modulate anxiety and insomnia by interacting with different neurotransmitter systems [4-9].

It has been reported that amygdala and hippocampus is one of critical regions for controlling aversive stress directly [10]. Monoamine neurotransmitters in the central nervous system, particularly serotonin (5-hydroxytryptamine, 5-HT) and norepinephrine (NE), are essential in regulating cognition, mood, and emotion. Abnormal 5$\mathrm{HT}$ and NE transmission plays a key role in the stress response and the mechanism of antidepressant action [11-13]. The relationship between $5-\mathrm{HT}$ and NE is also important for regulation of the sympathetic adrenomedullary system under stress conditions [14-16]. Recently, psychological stress (PCS) has attracted significant attention because it has been shown to accelerate the risk of various diseases including diabetes and cardiovascular disease as well as aging [17-19]. In addition, NE and 5-HT levels decreases following chronic stress exposure in male rats, while these levels are increased in female rats following the same stress [20,21]. Therefore, it is important to investigate the compounds affecting 5-HT and NE in males.

In previous studies, we have shown that VE decreases the plasma corticosterone levels in adult mice as well as D-galactose-induced aging mice [22]. Others have reported that dichloromethane extracts from roots and rhizomes of $V$. wallichii significantly increases $\mathrm{NE}$ and dopamine levels without any significant alterations in serotonin levels [23]. In this study, we investigate the effects of VE on stress-induced changes in monoamine metabolites following physical stress (PS) and PCS.

\section{Methods}

\section{Experimental animals}

Six-week-old male ICR mice were purchased from OrientBio Inc. (Seongnam, South Korea). They were housed at $23^{\circ} \mathrm{C}$ with $60 \%$ humidity and a 12-h light/12-h dark cycle, with free access to food and tap water. Animal handling and care conformed with the guidelines established in order to comply with current international laws and policies (NIH Guide for the Care and Use of Laboratory Animals, NIH Publication No. 85-23, 1985, revised 1996), and were approved by the Institutional Animal Care and Use Committee (IACUC) of Seoul
National University (SNU-120103-10). All of the experiments and procedures were designed to minimize the number of animals used and the suffering caused.

\section{Administration of VE}

Following a 2-week acclimation to laboratory conditions, the animals were divided into 5 groups $(n=7$ in each group): control, PS with vehicle (PS-V) group, PS with VE (PS-VE) group, PCS with vehicle (PCS-V) group, and PCS with VE (PCS-VE) group. VE was purchased from Naturex (Avignon, France). The animal groups and experimental protocol are summarized in Figure 1A. Distilled water (vehicle) or $100 \mathrm{mg} / \mathrm{kg} \mathrm{VE}$ was orally administered to mice once a day for 3 weeks. The dosage of $100 \mathrm{mg} / \mathrm{kg}$ was chosen on the basis of a previous report that VE increases serotonin levels in the hippocampus of depressive rats at $100 \mathrm{mg} / \mathrm{kg}$ dosage and not at $400 \mathrm{mg} / \mathrm{kg}$ dosage [24]. At this dose, VE also significantly reduces the plasma corticosterone levels as shown in a previous study [22].

\section{PS and PCS exposure}

PS and PCS models were developed in mice utilizing a communication box according to the method of Ogawa and Kuwabara [25]. Briefly, a communication box was divided into room $\mathrm{A}$ and room $\mathrm{B}$ with a transparent acrylic board $(16 \mathrm{~cm} \times 16 \mathrm{~cm} \times 64 \mathrm{~cm})$. Room $A$ included 8 small rooms with a plastic board-covered floor, and room $B$ included 8 small rooms with a metal gridexposed floor for electric insulation (Figure 1A). Mice in room $B$ were given an electrical shock $(0.3 \mathrm{~mA}$ for $10 \mathrm{~s}$ and rest for $2 \mathrm{~min}$ ) for $60 \mathrm{~min}$ through the floor and exhibited nociceptive stimulation-evoked responses, such as jumping up, defecating, and crying. Mice in room A were only exposed to the responses of mice in room B to establish PCS model. Mice were subjected to PS and PCS for 60 min every morning (11:00-11:30) for 3 days before they were killed. At the end of the exposure, the mice were kept in the cages for $1 \mathrm{~h}$ before they were taken out.

\section{Forced swimming test}

At $1 \mathrm{~h}$ after last stress exposure, the mice were placed inside a $25 \mathrm{~cm}$ glass cylinder (with a $14 \mathrm{~cm}$ diameter) containing $20 \mathrm{~cm}$ of water that was maintained at $24 \pm$ $2^{\circ} \mathrm{C}$ and were forced to swim for $6 \mathrm{~min}$. Their immobility times were recorded using the video-based Ethovision System during the last $4 \mathrm{~min}$ of the $6 \mathrm{~min}$ test.

\section{Corticosterone levels and tissue processing}

Mice from all 5 groups ( $n=7$ in each group) were anesthetized with $100 \mathrm{mg} / \mathrm{kg}$ of Zoletil $50^{\circ}$ (Virbac, Carros, France) at $2 \mathrm{~h}$ after FST test to measure the concentrations of corticosterone levels in serum and 5-HT, NE, and their respective metabolites (5-hydroxyindoleacetic 


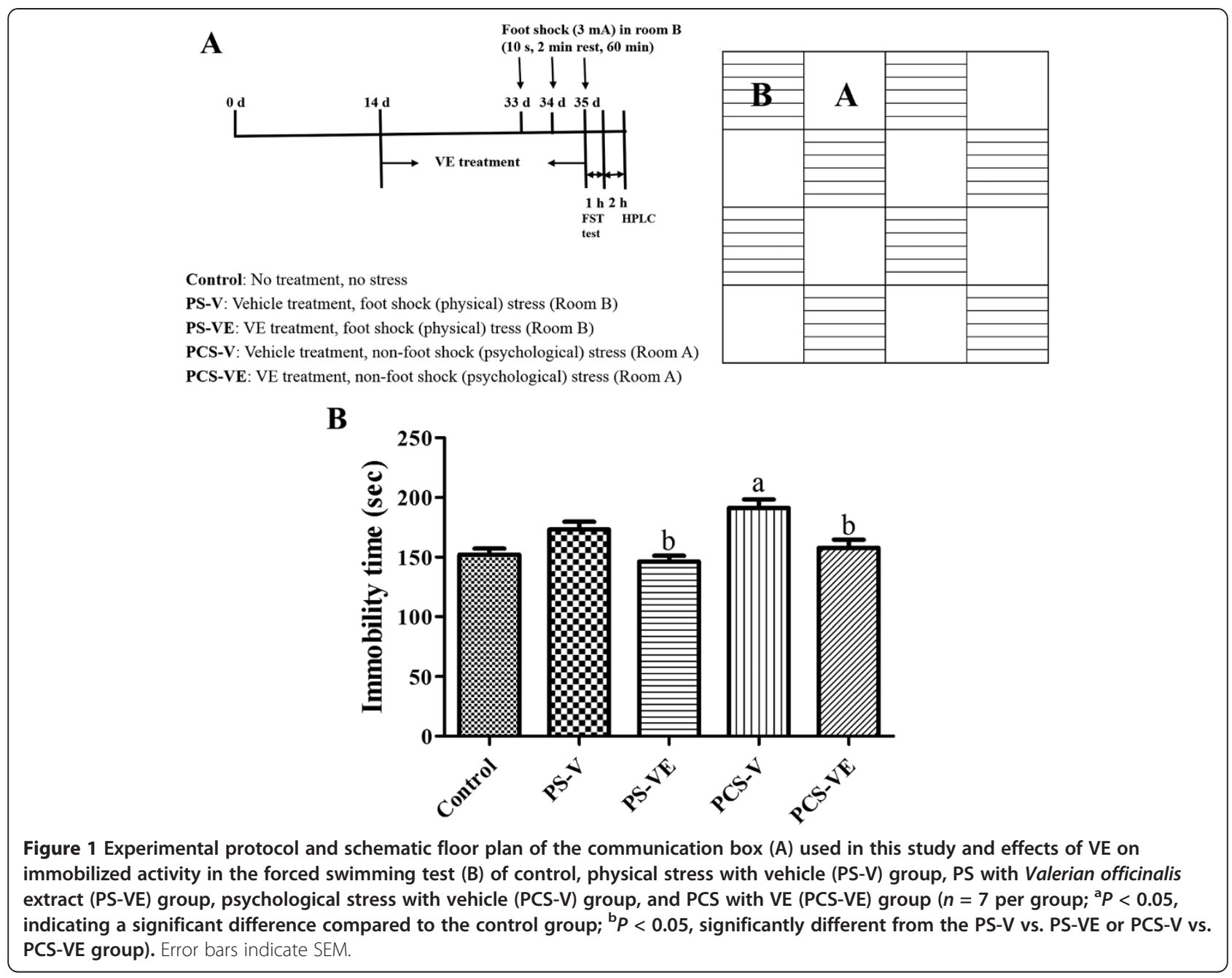

acid [5-HIAA] and 3-methoxy-4-hydroxyphenylethyleneglycol sulfate [MHPG-SO $\mathrm{M}_{4}$ ]) in the hippocampus and amygdala. Blood samples were obtained from each animal by cardiac puncture via the $1 \mathrm{ml}$ syringe before obtaining the hippocampus and dentate gyrus. The samples were allowed to clot and were then centrifuged for $30 \mathrm{~min}$ at $1,000 \mathrm{~g}$ to separate out the serum. Corticosterone was measured using a commercial enzymelinked immunosorbent assay (ELISA) kit (IBL, Hamburg, Germany) following the manufacturer's instructions. The absorbance was read at $450 \mathrm{~nm}$. Brain was removed from braincase and the hippocampus and amygdala were separated on ice, and the samples were frozen using liquid nitrogen.

\section{Monoamines and their metabolites in hippocampus and amygdala}

5-HT, NE, 5-HIAA, and MHPG-SO 4 concentrations were assessed in the mixture of hippocampal and amygdala samples by high-performance liquid chromatography (HPLC) as described by Nadaoka et al. [26]. The frozen tissues were fractured in $0.2 \mathrm{M}$ perchloric acid containing $0.1 \mathrm{mM}$ disodium ethylenediaminetetraacetic acid (EDTA) and isoproterenol as an internal standard. The homogenate was then centrifuged at $20,000 \times g$ for $15 \mathrm{~min}$. The supernatant was adjusted to $\mathrm{pH} 3.0$ with $1 \mathrm{M}$ sodium acetate and then passed through a $0.2-\mu \mathrm{m}$ regenerated cellulose filter. An aliquot of this filter was injected onto a $\mathrm{C}_{18}$ reverse-phase column $(250 \mathrm{~mm} \times$ $4.6 \mathrm{~mm}, 5 \mu \mathrm{m}$; Agilent Technologies, Santa Clara, CA) in a HPLC system (Agilent 1100 series) equipped with an electrochemical detector. The mobile phase used with this aliquot $(0.1 \mathrm{M}$ acetate-citrate buffer with $17 \%$ methanol) allowed for the separation of the two major monoamines 5-HT and NE and their respective metabolites, 5-HIAA and MHPG-SO 4 [27]. Sodium octyl sulfate $(190 \mathrm{mg} / \mathrm{L})$ was added as an ion-pairing agent, and EDTA $(5 \mathrm{mg} / \mathrm{L})$ was added as an antioxidant. Each peak area was normalized to isoproterenol concentration. The level of 5HT, NE and their metabolites were detected using a Waters 474 scanning fluorescence detector (Waters, USA) with its adequate excitation and emission wavelengths. 
The HPLC system was connected to a computer to quantify all compounds by comparing the area under the peaks with the area of reference standards with specific HPLC software (Chromatography Station for Windows). The turnover ratio of 5-HIAA to 5-HT is considered an index of the activity of cells that cause release of $5-\mathrm{HT}$, reuptake and metabolism to 5-HIAA.

\section{Statistical analyses}

The data represent the mean values for each experiment. To determine the effects of VE on PS and PCS, the differences between the means were statistically analyzed by using a one-way analysis of variance with Tukey's post-hoc test.

\section{Results}

Effects of VE on depressive-like behavior in the stressed mice

The immobility time of the PS-VE group was significantly decreased; it was $84.5 \%$ of that in the PS-V group. On the other hand, in the PCS-V group, immobility time was significantly increased to $125.6 \%$ of that in the control group. In the PCS-VE group, immobility time was significantly decreased compared to that in the PCS-V group (Figure 1B).

\section{Effects of VE on corticosterone levels following PS or PCS} Corticosterone levels were measured because changes in the level of plasma glucocorticoids are commonly used as a measure of stress in animals. In the control group, the plasma corticosterone level was $78.1 \mu \mathrm{g} / \mathrm{L}$. In the PS-V group, the corticosterone level was significantly increased and was 3.94 fold higher than that in the control group. In the PS-VE group, the corticosterone level was significantly decreased; it was $61.4 \%$ of that in the PS-V group, but was significantly higher than that in the control group. In the PCS-V group, the corticosterone level was 2.10 fold higher than that in the control group and was significantly lower than that in the PS-V group. In the PCS-VE group, the corticosterone level was significantly decreased; it was $66.8 \%$ of that in the PCS-V group and was not significantly different from that in the control group (Figure 2).

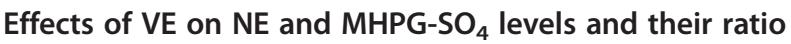 following PS or PCS}

$\mathrm{NE}$ and MHPG-SO 4 levels in the hippocampus and amygdala homogenates were 478.5 and $75.54 \mathrm{ng} / \mathrm{g}$ in the control group respectively. In the PS-V group, NE levels were significantly decreased, while $\mathrm{MHPG}-\mathrm{SO}_{4}$ levels were significantly increased compared to those in the control group. In the PS-VE group, NE levels were significantly increased compared to those in the PS-V group by similar to control group. MHPG-SO 4 levels in the PS-VE group were significantly decreased compared to those in the PS-V group, but $\mathrm{MHPG}-\mathrm{SO}_{4}$ levels were significantly higher than those in the control group. In the PCS-V group, NE levels were significantly lower compared to those in the control group (Figure 3A). In the PCS-VE group, NE levels were slightly increased

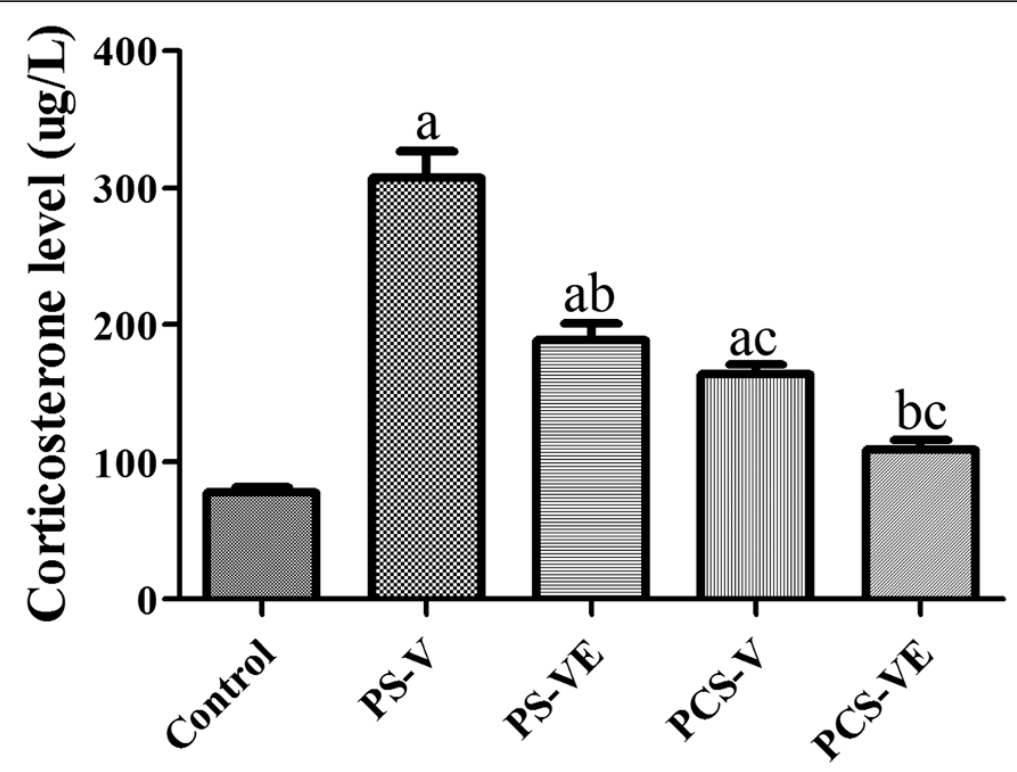

Figure 2 Plasma corticosterone levels in the control, physical stress with vehicle (PS-V) group, PS with Valerian officinalis extract (PS-VE) group, psychological stress with vehicle (PCS-V) group, and PCS with VE (PCS-VE) group ( $n=7$ per group; ${ }^{a}<<0.05$, indicating a significant difference compared to the control group; ${ }^{{ }^{b} P}<0.05$, significantly different from the PS-V vS. PS-VE or PCS-V vs. PCS-VE group; ${ }^{C} P<0.05$, significantly different from the PS-V vs. PCS-V or PS-VE vs. PCS-VE group). Error bars indicate SEM. 


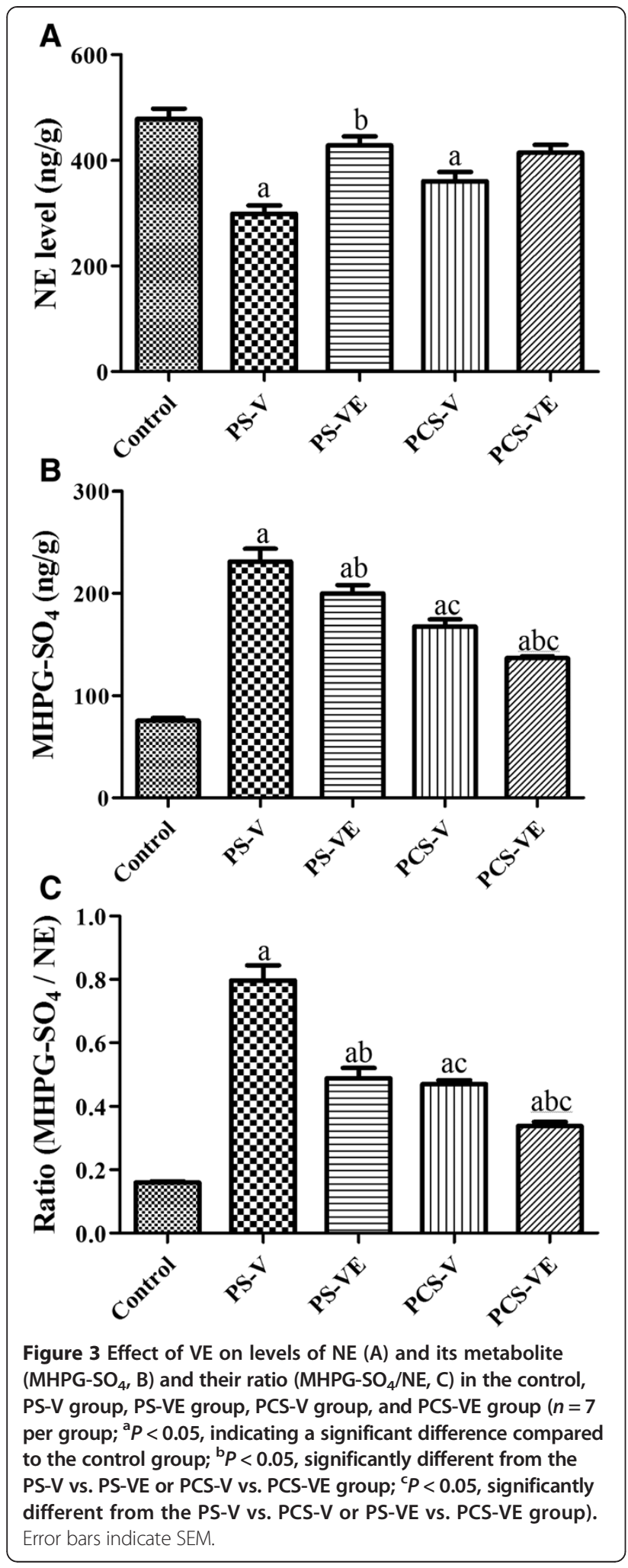

compared to those in the PCS-V group, although statistical significance was not detected. MHPG-SO $\mathrm{S}_{4}$ levels in the PCS-VE group were significantly decreased compared to those in the PCS-V group. However, MHPG-
$\mathrm{SO}_{4}$ levels were significantly higher than those in the control group (Figure 3B). Similarly, the ratio of MHPG$\mathrm{SO}_{4} / \mathrm{NE}$ was significantly increased in the PS-V and PCS-V groups compared to the control group. However, this ratio was significantly lower in the PCS-V group compared to the PS-V group. In the PS-VE and PCS-VE groups, the ratio of MHPG-SO $\mathrm{S}_{4} / \mathrm{NE}$ was significantly reduced compared to the PS-V and PCS-V groups, respectively (Figure 3C).

\section{Effects of VE on 5-HT and 5-HIAA levels and their ratio following PS or PCS}

In the control group, 5-HT and 5-HIAA levels in the hippocampus and amygdala homogenates were 342.2 and $307.1 \mathrm{ng} / \mathrm{g}$, respectively. 5-HT levels in the PS and PCS groups were not changed significantly (Figure 4A). In contrast, 5-HIAA levels were significantly varied between experimental groups. In the PS group, 5-HIAA levels were significantly increased compared to those in the control group. In the PS-VE group, 5-HIAA levels were markedly decreased compared to those in the PS group, although statistical significance was not detected. In the PCS-V group, 5-HIAA levels were significantly increased compared to the control group. In addition, 5-HIAA levels were higher than those in the PS group. In the PCS-VE group, 5-HIAA levels were significantly decreased compared to the levels in the PCS-V group and were similar to the levels in the control group (Figure 4B). The administration of VE to the PS group decreased the ratio of 5HIAA/5-HT prominently, but statistical significance was not achieved. In the PCS-VE group, the ratio of 5-HIAA/ 5-HT was significantly decreased (Figure 4C).

\section{Discussion}

There has been growing interest in PS and PCS, as they are important factors in many disorders, such as hypertension, gastric ulcers, affective disorders, and metabolic syndromes. In the present study, we designed the communication box to induce PS and PCS in mice because this device can induce both PS and PCS models simultaneously and aid in investigating the physical and physiological changes under psychological stress conditions [28,29].

The forced swimming test (FST) is a well-known screening tool for depressed animals [30,31]. Depression of active behavior happens in animals with exposure to highly stressful situations. In the present study, we observed that immobility time of PS-V group was moderately increased compared to that of the control group. In this study, we observed the immobility time was more prominently increased in the PCS-V group compared to that in the PS-V group. It was reported that the immobility time in the FST was increased by acute restraint stress in rat [32]. In addition, acute stress induced the 


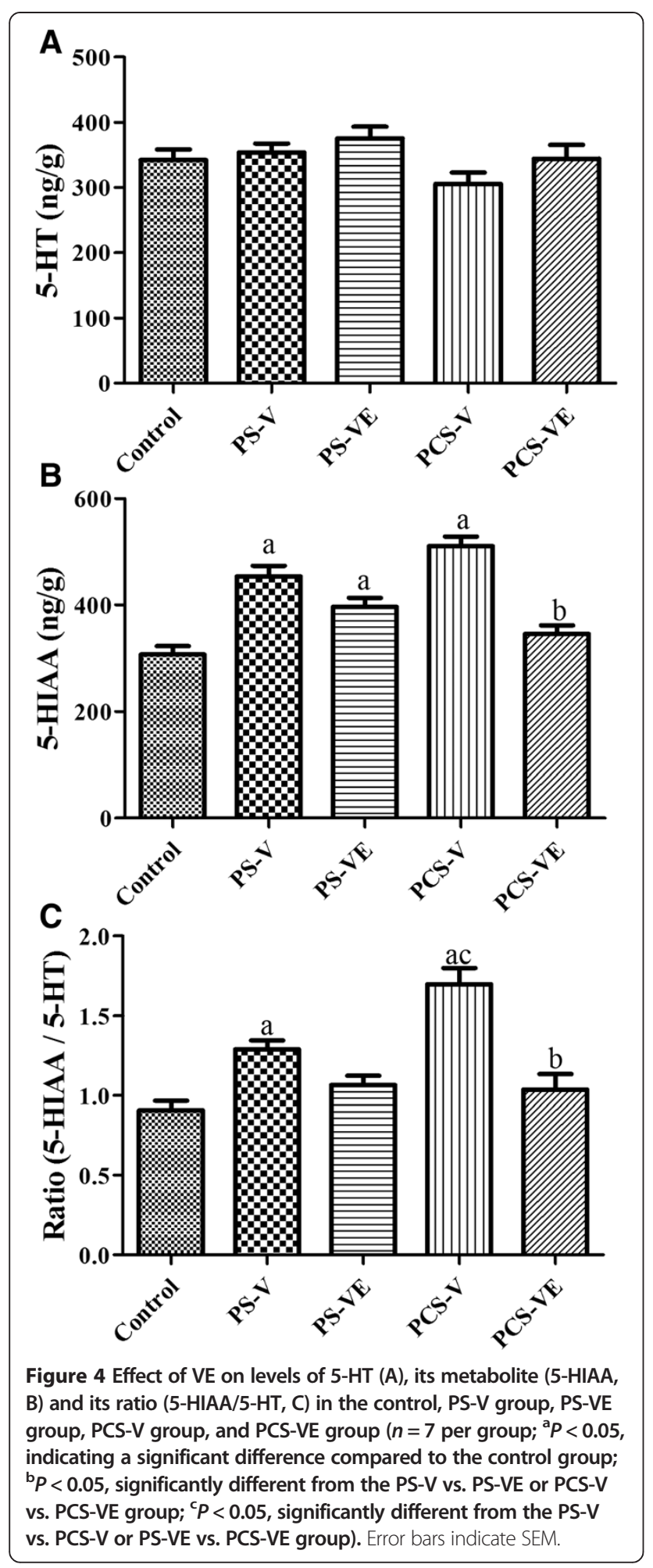

immobility time by $121 \%$ of control group in mice [33]. Similar to these studies, we observed that immobility time in the FST was decreased in both PS and PCS groups compared to that in the control group. In addition, the immobility time was significantly decreased in both VE-treated groups compared to that in respective vehicle-treated groups. The present result suggests that VE may ameliorate PS or PCS induced depression.

It was reported that a remarkable increase of plasma corticosterone level during and after both PS and PCS stress exposures [29,34]. Similar to these studies, we observed significant increase in plasma corticosterone after PS and PCS conditions in the present study. In addition, we found that VE administration significantly reduced increased plasma corticosterone levels after both PS and PCS. This result is supported by our and other previous studies showing that reduced the corticosterone levels in immobilization-induced stress mice and in chemically induced aging mice $[22,35]$. The present result suggests that VE could reduce increased corticosterone level by PS and PCS.

Next, we investigated the effects of VE on levels of $\mathrm{NE}, 5-\mathrm{HT}$, and their respective metabolites in the homogenates of the hippocampus and amygdala, which are regions most vulnerable to stress and the major targets for corticosterone, NE, and 5-HT [36-38]. NE cells are located in the locus coeruleus and lateral tegmental areas, and their fibers are projected into most brain regions including the hippocampus and amygdala [39]. MHPG-SO ${ }_{4}$ level has been considered to be more indicative of NE utilization in the brain [40-43]. In addition, it was reported that these amine-to-metabolite ratios are increased by restraint stress [44] and these ratios are very useful factor to determine the stress conditions in the central nervous system because antidepressants typically enhance monoaminergic neurotransmission by inhibiting neurotransmitter degradation or reuptake [45].

These results are supported by previous findings that PS causes a remarkable increase in NE turnover in various brain regions such as the cerebral cortex, midbrain, locus coeruleus, hypothalamus, amygdala, thalamus, and hippocampus, while PCS has been reported to cause an acute mild increase in NE turnover in the hypothalamus and amygdala [46]. Agonists of the 5- $\mathrm{HT}_{1 \mathrm{~A}}$ receptor and selective 5-HT reuptake inhibitors are clinically useful for treating various anxiety disorders $[47,48]$. 5-HT cells are mainly located in the midbrain raphe nuclei and their fibers are projected into the prefrontal cortex, amygdala, hippocampus, and nucleus accumbens [49,50]. Abnormalities in the 5-HT system in the brain causes depression and anxiety disorders, largely demonstrated by the fact that most antidepressants increase extracellular 5-HT level.

The dissociation of 5-HT and 5-HIAA was supported by previous studies on stress response showing that increased brain levels of 5-HIAA without affecting 5-HT concentrations under stress condition [51-54]. The ratio of 5-HIAA/5-HT was also significantly increased in the PS-V and PCS-V groups compared to the control group. 
The administration of VE to the PS or PCS group decreased the ratio of 5-HIAA/5-HT prominently (but not significantly) or significantly, respectively. Therefore, the present results suggest that PS or PCS stress is more prominently affected on changes of 5-HIAA levels than 5-HT levels, and VE administration could be reduced the ratio of 5-HIAA/5-HT via controlling of 5-HIAA levels in the PS or PCS condition. In addition, in both VE-treated groups, 5-HT levels also did not change significantly similar to previous study that showed any significant alterations in 5-HT levels after administration of dichloromethane extract from the roots and rhizomes of V. wallichii [23].

\section{Conclusion}

PS is induced by foot-shock stress, and PCS is generated by an exposure to the emotional responses caused by animal exposed to PS. PS and PCS animals significantly increase immobility time in forced swimming test, corticosterone levels in serum and turnover of 5-HT and $\mathrm{NE}$ in hippocampal and amygdala homogenates. PS dominantly modulates NE turnover, while PCS has a greater influence on 5-HT turnover. VE administration significantly suppresses the PS and PCS response by reducing the immobility time in forced swimming test, plasma levels of corticosterone and turnover of 5-HT and NE. These results suggest that VE could be ameliorated PS or PCS stress induced depression via control of plasma levels of corticosterone and turnover of 5- $\mathrm{HT}$ and NE.

\section{Competing interests}

The authors declare that they have no competing interests.

\section{Authors' contributions}

HYJ, DYY, WK, SMN, JWK, YSY, and IKH conceived the study, designed and conducted the experiments, and drafted the manuscript. JHC and YGK participated in designing and discussing the study. All authors have read and approved the final manuscript.

\section{Acknowledgements}

This Research was supported by High Value-added Food Technology Development Program, Ministry for Agriculture, Food and Rural Affairs, Republic of Korea (111118-032-HD110).

\section{Author details}

'Department of Anatomy and Cell Biology, College of Veterinary Medicine, and Research Institute for Veterinary Science, Seoul National University, Seoul 151-742, South Korea. ${ }^{2}$ Department of Anatomy, College of Veterinary Medicine, Kangwon National University, Chuncheon 200-701, South Korea. ${ }^{3}$ Central Research Center, Natural F\&P Co. Ltd, Cheongwon 363-883, South Korea.

Received: 11 April 2014 Accepted: 22 September 2014

Published: 11 December 2014

\section{References}

1. Hadley S, Petry JJ: Valerian. Am Fam Phys 2003, 67:1755-1758

2. De Oliveria DM, Barreto G, De Andrade DV, Saraceno E, Aon-Bertolino L, Capani F, Dos Santos El Bachá R, Giraldez LD: Cytoprotective effect of Valeriana officinalis extract on an in vitro experimental model of Parkinson disease. Neurochem Res 2009, 34:215-220.
3. Pereira RP, Fachinetto R, de Souza Prestes A, Wagner C, Sudati JH, Boligon AA, Athayde ML, Morsch VM, Rocha JB: Valeriana officinalis ameliorates vacuous chewing movements induced by reserpine in rats. J Neural Transm 2011, 118:1547-1557.

4. Malva JO, Santos S, Macedo T: Neuroprotective properties of Valeriana officinalis extracts. Neurotox Res 2004, 6:131-140.

5. Sudati JH, Fachinetto R, Pereira RP, Boligon AA, Athayde ML, Soares FA, de Vargas Barbosa NB, Rocha JB: In vitro antioxidant activity of Valeriana officinalis against different neurotoxic agents. Neurochem Res 2009, 34:1372-1379.

6. Ortiz JG, Rassi N, Maldonado PM, González-Cabrera S, Ramos I: Commercia valerian interactions with $\left[{ }^{3} \mathrm{H}\right]$ flunitrazepam and $\left[^{3} \mathrm{H}\right] \mathrm{MK}-801$ binding to rat synaptic membranes. Phytother Res 2006, 20:794-798.

7. Sichardt K, Vissiennon Z, Koetter U, Brattström A, Nieber K: Modulation of postsynaptic potentials in rat cortical neurons by valerian extracts macerated with different alcohols: involvement of adenosine $A_{1}$ - and $\mathrm{GABA}_{\mathrm{A}}$-receptors. Phytother Res 2007, 21:932-937.

8. Del Valle-Mojica LM, Cordero-Hernández JM, González-Medina G, RamosVélez I, Berríos-Cartagena N, Torres-Hernández BA, Ortíz JG: Aqueous and ethanolic Valeriana officinalis extracts change the binding of ligands to glutamate receptors. Evid Based Complement Alternat Med 2011, 2011:891819.

9. Del Valle-Mojica LM, Ayala-Marín YM, Ortiz-Sanchez CM, Torres-Hernández BA Abdalla-Mukhaimer S, Ortiz JG: Selective interactions of Valeriana officinalis extracts and valerenic acid with [H]glutamate binding to rat synaptic membranes. Evid Based Complement Alternat Med 2011, 2011:403591.

10. Maren S, Quirk GJ: Neuronal signalling of fear memory. Nat Rev Neurosci 2004, 5:844-852.

11. Ressler KJ, Nemeroff CB: Role of serotonergic and noradrenergic systems in the pathophysiology of depression and anxiety disorders. Depress Anxiety 2000, 12(Suppl 1):2-19.

12. Nestler EJ, Barrot M, DiLeone RJ, Eisch AJ, Gold SJ, Monteggia LM: Neurobiology of depression. Neuron 2002, 34:13-25.

13. Wong ML, Licinio J: From monoamines to genomic targets: a paradigm shift for drug discovery in depression. Nat Rev Drug Discov 2004 3:136-151

14. Khan S, Michaud D, Moody TW, Anisman H, Merali Z: Effects of acute restraint stress on endogenous adrenomedullin levels. Neuroreport 1999, 10:2829-2833

15. Tanaka M, Yoshida M, Emoto H, Ishii H: Noradrenaline systems in the hypothalamus, amygdala and locus coeruleus are involved in the provocation of anxiety: basic studies. Eur J Pharmacol 2000, 405:397-406.

16. Chen WW, He RR, Li YF, Li SB, Tsoi B, Kurihara H: Pharmacological studies on the anxiolytic effect of standardized Schisandra lignans extract on restraint-stressed mice. Phytomedicine 2011, 18:1144-1147.

17. Wales JK: Does psychological stress cause diabetes? Diabet Med 1995, 12:109-112.

18. Blumenthal JA, Babyak MA, Doraiswamy PM, Watkins L, Hoffman BM, Barbour KA, Herman S, Craighead WE, Brosse AL, Waugh R, Hinderliter A, Sherwood A: Exercise and pharmacotherapy in the treatment of major depressive disorder. Psychosom Med 2007, 69:587-596.

19. Epel ES: Psychological and metabolic stress: a recipe for accelerated cellular aging? Hormones (Athens) 2009, 8:7-22.

20. Bowman RE, Beck KD, Luine VN: Chronic stress effects on memory: sex differences in performance and monoaminergic activity. Horm Behav 2003, 43:48-59.

21. Luine VN: Sex differences in chronic stress effects on memory in rats. Stress 2002, 5:205-216

22. Nam SM, Choi JH, Yoo DY, Kim W, Jung HY, Kim JW, Kang SY, Park J, Kim DW, Kim WJ, Yoon YS, Hwang IK: Valeriana officinalis extract and its main component, valerenic acid, ameliorate D-galactose-induced reductions in memory, cell proliferation, and neuroblast differentiation by reducing corticosterone levels and lipid peroxidation. Exp Gerontol 2013, 48:1369-1377.

23. Sah SP, Mathela CS, Chopra K: Antidepressant effect of Valerianan wallichii patchouli alcohol chemotype in mice: behavioural and biochemical evidence. J Ethnopharmacol 2011, 135:197-200.

24. Tang JY, Zeng YS, Chen QG, Qin YJ, Chen SJ, Zhong ZQ: Effects of Valerian on the level of 5-hydroxytryptamine, cell proliferation and neurons in cerebral hippocampus of rats with depression induced by chronic mild stress. Zhong Xi Yi Jie He Xue Bao 2008, 6:283-288. 
25. Ogawa M, Kuwabara H: Psychophysiology of emotion-communication of emotion. Shinshin-Igaku 1966, 6:352-357.

26. Nadaoka I, Yasue M, Sami M, Kitagawa Y: Oral administration of Cimicifuga racemosa extract affects immobilization stress-induced changes in murine cerebral monoamine metabolism. Biomed Res 2012, 33:133-137.

27. Rowland NE, Dunn AJ: Effect of dexfenfluramine on metabolic and neurochemical measures in restraint-stressed ob/ob mice. Physiol Behav 1995, 58:749-754.

28. Endo Y, Shiraki K: Behavior and body temperature in rats following chronic foot shock or psychological stress exposure. Physiol Behav 2000, 71:263-268

29. Endo $Y$, Yamauchi $K$, Fueta $Y$, Irie M: Changes of body temperature and plasma corticosterone level in rats during psychological stress induced by the communication box. Med Sci Monit 2001, 7:1161-1165.

30. Porsolt $\mathrm{R}$, Bertin A, Jalfre M: Behavioral despair in mice: a primary screening test for antidepressants. Arch Int Pharmacodyn Ther 1977, 229:327-336.

31. Petit-Demouliere B, Chenu F, Bourin M: Forced swimming test in mice: a review of antidepressant activity. Psychopharmacology (Berl) 2005, 177:245-255.

32. Cancela L, Rossi S, Molina V: Effect of different restraint schedules on the immobility in the forced swim test: modulation by an opiate mechanism. Brain Res Bull 1991, 26:671-675.

33. Poleszak E, Wlaz P, Kêdzierska E, Nieoczym D, Wyska E, Szymura-Oleksiak J, Fidecka S, Radziwon-Zaleska M, Nowak G: Immobility stress induces depression-like behavior in the forced swim test in mice: effect of magnesium and imipramine. Pharmacol Rep 2006, 58:746.

34. Ishikawa M, Hara C, Ohdo S, Ogawa N: Plasma corticosterone response of rats with sociopsychological stress in the communication box. Physiol Behav 1992, 52:475-480.

35. Hosoi J, Tanida M, Tsuchiya T: Mitigation of stress-induced suppression of contact hypersensitivity by odorant inhalation. Br J Dermatol 2001, 145:716-719.

36. Henke PG, Ray A, Sullivan RM: The amygdala: emotions and gut functions. Dig Dis Sci 1991, 36:1633-1643.

37. Conrad CD: Chronic stress-induced hippocampal vulnerability: the glucocorticoid vulnerability hypothesis. Rev Neurosci 2008, 19:395-411.

38. Joëls M, Krugers H, Karst H: Stress-induced changes in hippocampal function. Prog Brain Res 2008, 167:3-15.

39. Moore RY, Bloom FE: Central catecholamine neuron systems: anatomy and physiology of the norepinephrine and epinephrine systems. Annu Rev Neurosci 1979, 2:113-168.

40. Stone EA: Stress and catecholamines. In Catecholamines and Behavior Edited by Friedhoff AJ. New York: Plenum; 1975:31-72.

41. Elsworth JD, Roth RH, Redmond DE Jr: Relative importance of 3-methoxy4-hydroxyphenylglycol and 3,4-dihydroxyphenylglycol as norepinephrine metabolites in rat, monkey, and humans. J Neurochem 1983, 41:786-793.

42. Kohno Y, Tanaka M, Nakagawa R, Toshima N, Nagasaki N: Regional distribution and production rate of 3-methoxy-4-hydroxyphenylethyleneglycol sulphate (MHPG-SO 4 ) in rat brain. $J$ Neurochem 1981, 36:286-289.

43. Meek JL, Neff NH: The rate of formation of 3-methoxy-4-hydroxyphenylethyleneglycol sulfate in brain as an estimate of the rate of formation of norepinephrine. J Pharmacol Exp Ther 1973, 184:570-575.

44. Sudha S, Pradhan N: Stress-induced changes in regional monoamine metabolism and behavior in rats. Physio/ Behav 1995, 57:1061-1066.

45. Baudry A, Mouillet-Richard S, Launay JM, Kellermann O: New views on antidepressant action. Curr Opin Neurobiol 2011, 21:858-865.

46. Tanaka M, Tsuda A, Yokoo H, Yoshida M, Ida Y, Nishimura H: Involvement of the brain noradrenaline system in emotional changes caused by stress in rats. Ann N Y Acad Sci 1990, 597:159-174.

47. Coplan JD, Gorman JM, Klein DF: Serotonin related functions in panicanxiety: a critical overview. Neuropsychopharmacology 1992, 6:189-200.

48. De Vry J: 5-HT $1 \mathrm{~A}$ receptor agonists: recent developments and controversial issues. Psychopharmacology (Berl) 1995, 121:1-26.

49. Holmes A: Genetic variation in cortico-amygdala serotonin function and risk for stress-related disease. Neurosci Biobehav Rev 2008, 32:1293-1314.

50. Steinbusch HW: Distribution of serotonin-immunoreactivity in the central nervous system of the rat-cell bodies and terminals. Neuroscience 1981, 6:557-618

51. Li JM, Kong LD, Wang YM, Cheng CH, Zhang WY, Tan WZ: Behavioral and biochemical studies on chronic mild stress models in rats treated with a
Chinese traditional prescription Banxia-houpu decoction. Life Sci 2003, 74:55-73.

52. Tõnissaar $M$, Herm L, Eller $M$, Kõiv K, Rinken A, Harro J: Rats with high or low sociability are differently affected by chronic variable stress. Neuroscience 2008, 152:867-876.

53. Adell A, Garcia-Marquez C, Armario A, Gelpi E: Chronic stress increases serotonin and noradrenaline in rat brain and sensitizes their responses to a further acute stress. J Neurochem 1988, 50:1678-1681.

54. Mitchell SN, Thomas PJ: Effect of restraint stress and anxiolytics on 5-HT turnover in rat brain. Pharmacology 1988, 37:105-113.

doi:10.1186/1472-6882-14-476

Cite this article as: Jung et al:: Valeriana officinalis root extract suppresses physical stress by electric shock and psychological stress by nociceptive stimulation-evoked responses by decreasing the ratio of monoamine neurotransmitters to their metabolites. BMC Complementary and Alternative Medicine 2014 14:476.

\section{Submit your next manuscript to BioMed Central and take full advantage of:}

- Convenient online submission

- Thorough peer review

- No space constraints or color figure charges

- Immediate publication on acceptance

- Inclusion in PubMed, CAS, Scopus and Google Scholar

- Research which is freely available for redistribution 